\title{
Análise da dignidade penal e carência de tutela penal nas pesquisas envolvendo seres humanos
}

Talita Ferreira Alves Machado ${ }^{1}$, Claudio Cohen ${ }^{2}$, Reinaldo Ayer de Oliveira ${ }^{3}$

\section{Resumo}

A evolução da humanidade estimula o desenvolvimento das tecnologias, notadamente no que tange às pesquisas envolvendo seres humanos. Nesse âmbito reside a proteção das pessoas ante os riscos das pesquisas. Este artigo analisa a dignidade penal e carência de tutela penal nas pesquisas envolvendo seres humanos. Nele é constatada a existência de situações graves que demonstram a necessidade desta tutela e a carência de instrumentos aptos a garantir a imperatividade de documentos que regulam a matéria. $\mathrm{O}$ artigo afirma que o Direito Penal é o meio estatal mais eficaz para a tutela da vida e integridade física. Salienta que a existência de termo de consentimento para a realização dessas pesquisas é necessária, mas não afasta, contudo, a responsabilidade penal eventualmente existente.

Palavras-chave: Dignidade penal. Carência de tutela penal. Pesquisas envolvendo seres humanos.

\section{Resumen}

Análisis de la dignidad criminal y la falta de protección penal en relación con la investigación en seres humanos

La evolución de la humanidad estimula el desarrollo de tecnologías, especialmente en lo que respecta a la investigación involucrando seres humanos. Ahí se encuentra la protección de las personas ante los riesgos de las investigaciones. Este artículo examina la dignidad criminal y la falta de tutela penal en las investigaciones involucrando seres humanos. En el artículo se constata graves situaciones que demuestran la necesidad de esta tutela y la falta de instrumentos capaces de garantizar la exigencia de los documentos que rigen la materia. El artículo afirma que el Derecho Penal es el medio estatal más efectivo a la protección de la vida e integridad física. Señala que es necesaria la existencia del consentimiento para llevar a cabo este tipo de investigación, pero no descarta, sin embargo, la responsabilidad penal que puede existir.

Palabras-clave: Dignidad criminal. Falta de protección penal. Investigación en seres humanos.

\begin{abstract}
Analysis of criminal dignity and the lack of criminal protection in relation to research involving human beings

The evolution of humanity encourages the development of technologies, especially in regard to research involving human beings. In this context lies the protection of people from the risks of research. The article analyzes the criminal dignity and the lack of criminal protection in relation to research involving human beings. It notes serious situations that demonstrate the need for this protection and the lack of instruments that guarantee the imperativeness of documents about this subject. It states that Criminal Law is the most effective way to protect life and physical integrity. The article says the consent form is necessary, but it doesn't avoid the criminal responsibility.
\end{abstract}

Key words: Criminal dignity. Lack of criminal protection. Research involving human beings.

1. Mestranda talita.alves@hotmail.com 2. Livre-docente ccohen@usp.br 3. Doutor rayer@usp.br - Universidade de São Paulo (USP), São Paulo/SP, Brasil. 
Vivemos em uma sociedade de risco, o que, definitivamente, não significa que os riscos atuais sejam maiores que os do passado. Apesar de hoje existir mais segurança, a sensação de risco é maior. Tal fato decorre das características desses riscos, que, atualmente, são em grande parte produzidos pelos seres humanos e, em tese, controláveis pelo Direito Penal.

Nesse contexto, os avanços tecnológicos muitas vezes criam novos riscos, podendo gerar, ou não, efeitos nocivos que trazem impacto ao Direito Penal. Outro aspecto importante diz respeito à extensão, tamanho e potência dos eventuais danos trazidos pelas novas tecnologias. Sob tal cenário, é certo que a política criminal não pode esperar o implemento do risco para agir, da mesma maneira que o Direito Penal não pode aguardar o resultado para só então atuar.

\section{Sociedade de risco}

Em virtude da evolução dinâmica da sociedade e da tecnologia, o trabalho do legislador tornouse muito complexo, o que faz com que tenha de usar técnicas que evitem a obsolescência imediata dos tipos penais e, ao mesmo tempo, acompanhem os avanços da "sociedade de risco": A sociedade de risco, novo paradigma da era industrial tardia, fruto dos excessos cometidos por uma evolução 'a todo custo' (...) que têm sido causadores de uma Pandora de riscos que se podem definir como invisíveis, incalculáveis, potencialmente ilimitados (tanto espacial e temporalmente como, ainda, quanto ao círculo de afetados), insusceptiveis de constituir objeto de seguro, que esbatem fronteiras tanto físicas (leia-se geográficas) como culturais - provocando uma espécie de igualdade na diferença entre todos aqueles que conosco partilham a aventura da vida, provocaram, e têm a tendência a provocar, sentimentos de insegurança, incerteza e medo nas pessoas e nas organizações ${ }^{1}$.

Por conta dessa complexidade que permeia a atividade legislativa, o ônus político de determinar as fronteiras entre aquilo que merece e aquilo que não merece a tutela do Direito Penal tem ficado a cargo do Poder Judiciário. Este poder, embora não esteja - de fato - preparado para isso, acaba por determinar a palavra e definir a decisão política sobre o risco, o que acontece por meio de mecanismos como Ação Direta de Inconstitucionalidade Genérica, Ação Direta de Inconstitucionalidade Supridora de Omissão, Ação Declaratória de Constitucionalida- de, Arguição de Descumprimento de Preceito Fundamental e súmulas vinculantes.

Esses mecanismos são instrumentos pelos quais o Poder Judiciário determina, em certas hipóteses, a palavra sobre o risco, notadamente pela judicialização de políticas e pela ampliação dos poderes dos magistrados. De fato, as relevantes e aceleradas transformações econômicas, políticas e científicas exigem uma mudança de atitude do Judiciário. Essa nova organização social impacta também na dogmática do Direito Penal, que não consegue se adequar à sociedade, frente às novidades que surgem a cada dia. É nesse contexto que se viabiliza a discussão acerca da dignidade penal e da carência de tutela penal nas pesquisas envolvendo seres humanos - pesquisas essas que podem resultar em situações marcadas por risco de impacto considerável à sociedade.

\section{Pesquisas envolvendo seres humanos}

Ages de tal maneira que uses a humanidade, tanto na tua pessoa como na pessoa de qualquer outro, sempre e simultaneamente como fim e nunca simplesmente como meio (Kant) ${ }^{2}$. Acerca do tema, é oportuno mencionar que se entende por pesquisa envolvendo seres humanos aquela que, individual ou coletivamente, envolva o ser humano de forma direta ou indireta, em sua totalidade ou partes dele, incluindo o manejo de informações ou materiais ${ }^{3}$.

A Resolução 1 do Conselho Nacional de Saúde (CNS), revogada pela Resolução 196/96, considerava em seu artigo $7^{\circ}$, como risco da pesquisa, a probabilidade de o indivíduo sofrer algum dano como consequência imediata ou tardia do estudo. Para efeito deste regulamento, as pesquisas eram classificadas em três categorias: pesquisas sem riscos, com riscos mínimos e com risco maior que o mínimo ${ }^{4}$. A Resolução CNS 196/96, que revogou a anterior, dispõe acerca dos riscos considerando no item $\mathrm{V}$ que toda pesquisa envolvendo seres humanos envolve risco. 0 dano eventual poderá ser imediato ou tardio, comprometendo o indivíduo ou a coletividade ${ }^{5}$.

A evolução da humanidade estimula a necessidade de desenvolver e aprimorar as tecnologias, notadamente no que tange às pesquisas envolvendo seres humanos, quer com vistas à prevenção, quer para o tratamento/cura de enfermidades. O anseio por uma vida mais longa e de melhor qualidade incentiva tais pesquisas. Como esclarecem Oliveira e Anjos Filho: 
Para que esses desejos se tornem viáveis é preciso conhecer cada vez mais profundamente a complexa máquina que é o corpo humano, desenvolver novos fármacos, medicamentos, vacinas e terapias para combater doenças, descobrir a 'fonte da juventude' através de métodos de desaceleração - ou quiçá interrupção - da degeneração celular, dentre outras possibilidades e desafios. A concretização desses objetivos depende de inúmeros fatores ligados à pesquisa cientifica, dentre os quais (...) a experimentação em seres humanos ${ }^{6}$.

A própria Constituição Federal, em seu artigo 218, dispõe: O Estado promoverá e incentivará o desenvolvimento científico, a pesquisa e a capacitação tecnológicas ${ }^{7}$. Os parágrafos deste artigo especificam normas para fomento, incentivo e custeio da atividade de pesquisa.

A pesquisa é, portanto, incentivada e, muitas vezes, até mesmo financiada pelo próprio Estado, sendo necessário, contudo, ter em mente que se deve encontrar uma forma menos artificial e anacrônica de preservação e tutela da vida (...) para acompanharmos sem medo as revoluções a que demos causa ${ }^{8}$. Assim, o objeto da proteção nesse âmbito deve ser indistinto, ou seja, independente do sexo, idade, cor, raça, origem, condição social, capacidade de entendimento e de autodeterminação. $E$ aí reside a questão da experimentação envolvendo seres humanos e a proteção das pessoas sobre os riscos das pesquisas.

A bioética, nesse âmbito, reflete acerca da eticidade das pesquisas envolvendo seres humanos. A relevância das pesquisas envolvendo seres humanos é inquestionável, pois constituem mecanismo que busca opções de prevenção e tratamento em benefício do ser humano. Assim, podem envolver tanto a observação quanto a intervenção física, química ou psicológica, bem como utilizar registros que contenham informações sobre determinados indivíduos.

Com efeito, o atual estágio de desenvolvimento da medicina pode ser atribuído, em boa parte, às pesquisas envolvendo seres humanos, pois essas permitiram diagnósticos mais precisos, terapias mais adequadas e maior expectativa e qualidade de vida às pessoas. Conforme esclarece a própria Resolução CNS 196/96, as pesquisas envolvendo seres humanos sempre implicam em risco e, em grande parte das vezes, são invasivas. Deve-se, por conseguinte, considerar a necessidade de resguardar a dignidade do sujeito de pesquisa e assegurar seus direitos.

A variação dos padrões éticos adotados nessas pesquisas desperta a atenção para um estudo mais detalhado do tema. O trabalho em tela tem como objetivo analisar a dignidade penal e a carência de tutela penal relativamente às pesquisas envolvendo seres humanos.

\section{Dignidade penal, bem jurídico e critérios de criminalização}

A dignidade penal representa a análise da necessidade ou não de tutela penal em uma determinada situação. Mais do que isso, por força do princípio da subsidiariedade do Direito Penal, significa a análise da carência ou não de tutela penal na hipótese. A esse respeito, Alice Bianchini afirma:

O Direito Penal se presta à proteção de valores fundamentais à vida do homem em sociedade. Isto, porém, não quer significar que em toda e qualquer oportunidade em que uma conduta ofenda tais valores haja necessidade de se recorrer a ele. Também pode suceder de o bem não carecer de proteção penal em toda a sua extensão. As questões que envolvem essa problemática inserem-se na análise da legitimidade criminalizadora, que passa por uma série de verificações até chegar-se a uma conclusão final acerca do assunto ${ }^{9}$.

A mesma autora esclarece que, primeiramente, há que se analisar, na hipótese, o merecimento da tutela penal, que decorre da conjugação da dignidade do bem jurídico e da ofensividade da conduta. Em segundo lugar, avalia-se a necessidade dessa tutela, de forma que, quanto mais importante for o bem e mais danosa a conduta que se procura interditar por meio do Direito Penal, mais necessária a sua intervenção e menos certeza se pode exigir de que outros meios poderiam, suficientemente, proteger o bem.

Ressalte-se, a esse respeito, a existência de critérios para definir como e quando criar a lei penal. São os critérios de seleção de crimes e de cominação de penas, nos quais o legislador deve se pautar ao formular as normas incriminadoras, a fim de garantir a defesa das liberdades individuais e do regime democrático. Também deve ser levado em conta o necessário respeito à própria condição humana e à racionalidade do sistema penal, definida por Ripollés como a capacidade para elaborar, no âmbito desse controle social, uma decisão legislativa que atenda a dados relevantes da realidade social e jurídica sobre os quais ela incide ${ }^{10}$. A análise desses critérios de criminalização revela a dificuldade do legislador em trabalhar com os bens jurídicos. 
Há muitas teorias acerca do que seria o bem jurídico, podendo-se afirmar, em suma, que bem jurídico é a expressão de um interesse da pessoa ou da comunidade na manutenção ou integridade de um certo estado, objeto ou bem em si mesmo socialmente relevante e por isso juridicamente reconhecido como valioso ${ }^{9}$. Em última análise, é o valor protegido por uma determinada incriminação. Assim, não havendo bem jurídico que a justifique, a conduta tipificada deve ser descriminalizada ou, no caso de ainda não haver tipo penal, não haverá porque criá-lo.

Essa análise revela, portanto, a existência ou não de dignidade penal na espécie tratada, ou seja, a existência ou não de merecimento e carência de tutela penal.

Convém mencionar ainda que, com relação aos critérios de criminalização, apenas pode ser criminalizada a conduta que fira bem jurídico previsto na Constituição, que assuma valor de direito fundamental. Importante ressaltar que a conduta pode ser criminalizada e não deve. Apenas o será quando se verificar que há necessidade e carência de tutela penal. Essa análise compete ao legislador, que deverá fazer a leitura da Constituição como instrumento que autoriza incriminações e não as obriga. Isso evita que se trabalhe de forma simplesmente reativa ao se legislar. Nesse sentido, a Constituição influencia a matéria a ser criminalizada, não a determina, porém ${ }^{9}$.

$\mathrm{Na}$ tarefa legislativa, portanto, ao se criar os tipos penais deve-se ter em mente tanto o desvalor da ação quanto o desvalor do resultado, ressaltando-se que só haverá tipificação diante de resultados lesivos ou perigosos ao bem jurídico. Considerando a essencialidade dos bens jurídicos ora tratados e as intoleráveis ofensas das quais se quer proteger, torna-se justificável o debate acerca da necessidade de elaboração de lei penal que disponha sobre as pesquisas envolvendo seres humanos. Ademais, nessas hipóteses, a fim de se evitar abusos, a pena, possivelmente, seria o único e último recurso para a proteção do bem jurídico ${ }^{2}$.

\section{Histórico normativo}

Como se sabe, o primeiro documento que tentou disciplinar a realização de pesquisas envolvendo seres humanos foi o Código de Nüremberg. 0 extermínio em massa de judeus e outras minorias étnicas nos campos de concentração revelou-se genocídio, consternando o mundo. Dentre as formas de aniquilarseres humanos nesses campos, identificaram-seas experiências clínicas. Realizadas em nome da ciência e do desenvolvimento de um poderio bélico, esses estudos, levados a cabo por médicos nazistas, também chocaram a comunidade internacional.

O conhecimento acerca desses fatos sensibilizou as pessoas e tornou evidente a ambivalência das ciências e das técnicas em relação aos aspectos da ética e da moral. Compreendeu-se, então, que progresso científico não é sinônimo de progresso da humanidade. Para tal entendimento, contribuiu o fato de as atrocidades cometidas nas pesquisas nazistas, realizadas em condições absolutamente desumanas e, sobretudo, em pessoas que não deram seu consentimento, terem sido condenadas pelo Tribunal de Nüremberg, em 1947.

Deste julgamento surgiu o Código de Nüremberg, que trata, fundamentalmente, de definir normas de experimentação em seres humanos. Destacam-se o consentimento livre e esclarecido do sujeito da pesquisa; experimentação em animal precedendo experimentação em seres humanos; ausência de risco; qualificação do experimentador; interrupção do experimento a qualquer momento dos ensaios. Sem dúvida, apoiada na responsabilidade ética do profissional, este código instituiu a obrigatoriedade do consentimento informado do indivíduo que participa como sujeito de uma pesquisa.

Concomitantemente, em 1948, a Declaração Universal dos Direitos Humanos, concebida como direitos do indivíduo ou da pessoa, reafirma a dignidade da pessoa humana: sua liberdade imprescritível de dispor de si próprio (de sua existência, do seu corpo). Os direitos humanos consagram, no seio da sociedade democrática, o princípio da autonomia individual contra todas as tutelas e poderes abusivos. A base filosófica desses direitos humanos virá tornar-se, progressivamente, fonte de inspiração para parte da reflexão sobre a ética e a bioética.

o Código de Nüremberg e a Declaração Universal dos Direitos Humanos mudaram a história das relações entre pesquisadores e sujeitos da pesquisa, introduzindo normas que consagraram os direitos individuais e a autonomia. Neles é detalhada a maneira como a pessoa humana deve ser respeitada quando na condição de sujeito de um procedimento de pesquisa. É enfatizado o respeito a sua decisão, de acordo com sua capacidade e autodeterminação. A expressão de sua decisão é um consentimento que passa a predominar em declarações e normas de pesquisa em seres humanos.

Também a Declaração de Helsinque avança no estabelecimento de normas fundamentais no cam- 
po da ética em pesquisas biomédicas. O consentimento informado reforça o conceito de autonomia do ser humano e amplia as responsabilidades do pesquisador. A Declaração avança porque define que o interesse dos sujeitos de pesquisa deve prevalecer sobre os interesses da ciência e os da sociedade; aponta as dificuldades do consentimento informado em situações específicas de dependência e incapacidade e cria as comissões de ética, independentes, para avaliação dos protocolos de pesquisa ${ }^{11}$ : determinada pessoa ou população pode ser objeto de pesquisa para desvendar doenças que a afligem ou para desnudar as razões pelas quais é menos suscetivel ou não é atingida por determinada moléstia que afeta aos demais seres humanos ${ }^{6}$.

\section{Necessidade e carência de tutela penal}

Faz-se oportuno mencionar que já houve na história situações suficientemente graves a demonstrar a possível necessidade de tutela penal quanto às pesquisas envolvendo seres humanos e, até mesmo, a evidenciar a carência dessa tutela. Nesse contexto, não se pode simplesmente esperar a ocorrência de um caso com repercussão de gigantescas proporções para que o Direito Penal aja, o que não significa dizer que se deva criar uma lei com tipos abertos a ponto de não traduzirem a taxatividade que se espera dos tipos penais.

Destarte, pelo até aqui exposto, acredita-se, sim, na necessidade do debate sobre a possibilidade de se elaborar legislação penal a respeito das condutas que envolvem as pesquisas em seres humanos. Ademais, muito embora - conforme já mencionado - a Constituição Federal incentive a pesquisa, as normas de garantia nela inseridas acabam por se tornar ineficazes diante da exagerada delegação de poder que o legislador confere a órgãos administrativos $^{2}$.

Sobre o ensino e pesquisa médica, o Código de Ética Médica (CEM), aprovado pela Resolução CFM 1.931, de 17 de setembro de 2009, em seu Capítulo XII determina que é vedado ao médico participar de qualquer tipo de experiência envolvendo seres humanos com fins bélicos, políticos, étnicos, eugênicos ou outros que atentem contra a dignidade humana (art. 99), bem como deixar de obter aprovação de protocolo para a realização de pesquisa em seres humanos, de acordo com a legislação vigente (art. 100). Além disso, o médico deve obter do paciente ou de seu representante legal o termo de consentimento livre e esclarecido para a realização de pes- quisa envolvendo seres humanos, após as devidas explicações sobre a natureza e as consequências da pesquisa (art. 101) - o parágrafo único estende essa garantia aos menores de idade.

Além desses aspectos fundamentais para assegurar a ética em pesquisa, o art. 102 do CEM dispõe sobre a utilização da terapêutica correta, quando seu uso estiver liberado no País, e o parágrafo único define que a utilização de terapêutica experimental é permitida quando aceita pelos órgãos competentes e com o consentimento do paciente ou de seu representante legal. Também os artigos subsequentes, do 103 ao 110, apontam aspectos fundamentais para a manutenção de padrões éticos do profissional pesquisador ${ }^{12}$.

Depreende-se da leitura dos dispositivos acima os objetivos: 1) proteção da dignidade da pessoa humana; 2) resguardo do sujeito de pesquisa; 3) destaque da importância do termo de consentimento e; 4) ausência de conflitos de interesses e de intuitos eminentemente lucrativos nas pesquisas envolvendo seres humanos. 0 art. 99, por exemplo, proíbe a realização de pesquisas envolvendo seres humanos que atentem contra a dignidade humana. Assim, o bem jurídico tutelado por essa norma é a própria dignidade da pessoa humana, cuja violação ocorre nas hipóteses em que as pesquisas possuem fins não atrelados ao benefício comum da humanidade.

0 art. 100, por sua vez, veicula a proibição de realizar pesquisas não aprovadas previamente, 0 que permite concluir que, ausente um regramento específico para direcionar a pesquisa envolvendo seres humanos, é possível que ela se desvie dos interesses altruístas que devem orientá-la, o que é vedado pelo CEM. $O$ art. 104 proíbe ao médico deixar de ser, profissional e cientificamente, independente em relação aos financiadores da pesquisa. Assim, veda que o médico atue movido por interesses lucrativos. $\mathrm{O}$ artigo seguinte busca evitar o conflito de interesses entre o sujeito de pesquisa e pesquisador, pois impede a realização de pesquisa quando houver relação direta ou indiretamente de dependência ou subordinação entre essas pessoas. $O$ art. 106 pretende evitar que o sujeito de pesquisa seja enganado pelo pesquisador, por meio da utilização de placebo e, por fim, o art. 109 destaca a importância de que sejam evitados os conflitos de interesses, ainda que em potencial.

Com efeito, os objetivos que podem ser deduzidos das vedações impostas aos médicos pelo CEM são de alta relevância. No mais, faz-se necessário mencionar o controle realizado pela Anvisa, relativo 
ao fornecimento de autorização para a realização de pesquisa clínica com medicamentos e produtos para a saúde. Há que se fazer a ressalva, todavia, de que inexiste, sejam nas vedações descritas no CEM, seja no controle realizado pela Anvisa, previsão de sanção proporcional à gravidade de eventuais violações que possam ser praticadas.

A Resolução 196/96 e resoluções complementares do CNS, juntamente com o CEM, constituem um conjunto de normas que tratam da pesquisa envolvendo seres humanos, regulando sua aplicação no país. É interessante observar que as diretrizes por elas traçadas ao regulamentarem as pesquisas poderiam servir de base para a formulação dos tipos penais que tutelassem os seres humanos nas pesquisas de que fossem sujeito.

A despeito da existência dessas regulamentações há carência de instrumentos imperativos que garantam a exigibilidade dos referidos documentos ${ }^{6}$, vez que, apesar da lesividade que pode decorrer de determinadas pesquisas, as sanções previstas para as violações possíveis talvez não sejam aptas a evitar novos e maiores abusos. Nesse sentido, pode-se mencionar como exemplo o inciso II, do Capítulo XIV (Disposições gerais) do CEM, que prevê: Os médicos que cometerem faltas graves previstas neste Código e cuja continuidade do exercício profissional constitua risco de danos irreparáveis ao paciente ou à sociedade poderão ter o exercício profissional suspenso mediante procedimento administrativo específico ${ }^{12}$.

A suspensão do exercício profissional, a depender da gravidade da situação, não atende à proporcionalidade que deve pautar o estabelecimento de sanções. A pergunta que deve ser feita nesse cenário é: podem os códigos éticos obrigar os cientistas a colocar os interesses das cobaias humanas acima daqueles da sociedade e da ciência? ${ }^{8}$ Refletindo a respeito, pergunta-se se o Estado, agindo de maneira coercitiva, poderia garantir que pesquisas envolvendo seres humanos fossem desenvolvidas respeitando a pessoa humana como um fim em si mesma e não como um instrumento? Nesse sentido, cabe destacar que apenas havendo lesividade ou potencialidade de sua ocorrência é que a atuação do Direito Penal se justificaria.

Assim, fala-se na impossibilidade de criminalização de condutas éticas ou morais que decorram de um sistema de valores próprio do indivíduo ou de determinadas subculturas - devendo o Estado, portanto, tolerá-las e respeitá-las. Paralelamente, há o dever de criminalizar condutas que atentem ou exponham a perigo concreto bens imprescindí- veis a uma qualificada existência do indivíduo em sociedade. É o princípio da lesividade, que assegura que as sanções penais só serão utilizadas quando um comportamento lesionar direitos de outras pessoas $^{9}$.

Nesse sentido, pode-se mencionar como exemplo fato ocorrido no início dos anos 80, quando o chefe da comunidade indígena Ucluelet autorizou a utilização de amostras, de seu sangue, para pesquisa sobre artrite, cujo objetivo era avaliar aspectos genéticos associados às doenças reumatológicas. O geneticista responsável coletou sangue de outros 900 indígenas. No final da década, o geneticista mudou de país (do Canadá para os Estados Unidos), levando consigo todas as amostras de sangue. Desde a mudança, os indígenas não obtiveram resposta sobre o que havia sido feito com o material biológico estocado. Em 2000, ficaram sabendo que o pesquisador havia utilizado este mesmo material biológico para outros estudos, em diferentes locais do mundo, sem ter solicitado novo consentimento. Atualmente, o pesquisador é diretor do Instituto de Antropologia Biológica da Universidade de Oxford, na Inglaterra. $O$ conselho tribal reuniu-se, no final de 2000, para solicitar a devolução das amostras, para evitar outros usos indevidos ${ }^{13}$.

$\mathrm{Na}$ situação descrita pode-se observar que, muito embora tenha havido desrespeito à autorização inicialmente concedida para a pesquisa, já que essa foi estendida a outros membros da tribo, além de ter sido utilizado o material biológico para outros estudos que não aquele afirmado a princípio, não houve lesão àquelas pessoas que participaram da pesquisa, apta a justificar a intervenção do Direito Penal. Assim, o referido exemplo não pode ser reputado digno e carecedor de tutela penal.

Deve-se observar que nesse debate estão em jogo valores sociais e humanos que demandam pronunciamentos sobre sua relevância, de forma que parece necessária a existência de regulamentação jurídica. De um lado, há o temor decorrente das ameaças possíveis à vida, à integridade física e à dignidade da pessoa humana; de outro, há o clamor pelos benefícios que pesquisas envolvendo seres humanos podem trazer. Em meio a esses dois extremos, o Direito não pode se colocar como mero normatizador de conflitos sociais, impedindo o desenvolvimento científico, tampouco pode se manter omisso - deixando, apenas a cargo da ética científica, questões relevantes para a humanidade e que demandam conjugação de conhecimento e de esforços para serem melhor compreendidas ${ }^{14}$. 
A atuação do Direito Penal nesse âmbito deve ser discutida, haja vista que a matéria afeta as necessidades do sistema em seu conjunto, ou seja, transcende o conflito entre as pessoas diretamente envolvidas nessas pesquisas, sendo socialmente danosa sob a perspectiva dos interesses gerais. 0 referido conflito apresenta potencialidade de generalização, de forma que, não agindo o Direito Penal, os efeitos perturbadores que poderão ser gerados certamente serão mais graves do que os até hoje observados, notadamente ante a falta de responsabilização adequada dos causadores de danos no contexto discutido.

Diante desta constatação, é importante verificar o que já foi feito nesse cenário. Assim, se há legislação penal, por exemplo, acerca dos transplantes, certo é que houve dignidade penal a amparar essa atuação. Destarte, por que não haveria dignidade penal com relação às pesquisas envolvendo seres humanos, se o bem jurídico tutelado, em ambas as situações, abrange a vida, a integridade e a dignidade humanas?

Não é que se acredite que o fato de ser direito fundamental (na espécie, direito à vida, direito à integridade e direito à dignidade) implique em necessária proteção pelo Direito Penal. Tampouco que para que um direito fundamental como tal seja reconhecido, tenha de ser penalmente protegido. A questão é realmente de proporcionalidade e razoabilidade ante as circunstâncias de notáveis necessidade e carência de tutela penal quanto às pesquisas envolvendo seres humanos.

A criação de tipos penais, portanto, parece adequada ao atendimento dos anseios ora expostos. A observância da legalidade e da taxatividade traria a segurança que se espera do Direito Penal. Ademais, a intervenção do Direito Penal nesse âmbito se justificaria, também, em virtude da existência de uma indústria farmacêutica com intuito eminentemente lucrativo.

Não se olvide, ademais, que a dignidade da pessoa humana, a integridade física e a vida são bens jurídicos de importância considerável, que fazem com que o Direito Penal seja o meio estatal mais eficaz para sua tutela, justificando a tipificação de determinadas condutas. E é justamente na tipificação das condutas que se costuma falar no princípio da idoneidade, pelo qual o legislador apenas deve criminalizar certo comportamento após se assegurar, empiricamente, acerca de sua utilidade e eficácia para o alcance da proteção que objetiva. No caso sob exame, presente a idoneidade da tutela, pois (...) Em outros países (...) recorreu-se ao mais grave de todos os controles sociais formais, ou seja, ao Direito Penal, por entender-se que os sistemas jurídicos extrapenais se revelaram insuficientes e inadequados na tutela de bens jurídicos da mais alta hierarquia constitucional, ameaçados pela biotecnologia ${ }^{14}$.

A lei penal, nessa hipótese, traduzir-se-á em uma forma de se evitar certas práticas indicando um limite máximo de pena para elas. Apenas com a tipificação das condutas é que se tornará possível a intervenção estatal, portanto. Os tipos penais a serem criados devem refletir o consenso social, formado a partir de um debate interdisciplinar, apto a elucidar as consequências das pesquisas envolvendo seres humanos.

Convém ressaltar que tal tutela não deve ser feita de maneira apressada, apenas como reação à opinião midiática, mas sim pormenorizadamente elaborada, haja vista que, como sabido, o Direito Penal é a última ratio. $\mathrm{O}$ que se deve ter em mente é que a proporcionalidade tem de estar presente na formulação desses tipos. Assim, devem ser postos em uma balança, de um lado, aquilo que se pretende proibir, sob a ameaça da pena e, de outro, a eficácia concreta da ação criminosa. $O$ critério a ser empregado, então, deve se pautar na gravidade do fato que se busca prevenir, conforme a capacidade de o Direito Penal modificar sua atuação.

\section{Tutela penal a par da legislação existente}

Como se sabe, algumas condutas relacionadas às pesquisas envolvendo seres humanos que poderiam ser criminalizadas subsumem-se a tipos já previstos no Código Penal, a exemplo da lesão corporal (art. 129, CP) e do homicídio (art. 121, CP). Contudo, a especificidade da situação ora discutida por si só é argumento que justifica a criação de lei específica a respeito do tema.

Além disso, apenas na publicação dos resultados das pesquisas é que costumam aparecer os problemas havidos durante sua realização. Fatores como esses certamente confluem para obnubilar muitas das condutas potencialmente criminosas praticadas durante a realização das pesquisas envolvendo seres humanos. Faz-se também importante observar que a indústria por detrás das pesquisas envolvendo seres humanos é grandiosa e, muitas vezes, descumpre as regras éticas estabelecidas para o trabalho que realiza. Assim, o contexto no qual as pesquisas são desenvolvidas é fator do qual se pode extrair a carência de tutela penal a esse respeito. 
Para exemplificar e também justificar a tutela específica em certos contextos, pode-se mencionar a conhecida Lei Maria da Penha ${ }^{15}$. Apesar das condutas criminosas praticadas contra a mulher já encontrarem resposta penal no ordenamento jurídico vigente, a lei foi criada ante a necessidade de se definir o que seria a violência doméstica e familiar contra as mulheres, bem como estabelecer mecanismos para prevenir e reduzir esse tipo de violência, além de definir instâncias, mecanismos e políticas para prestar assistência às vítimas.

Igualmente ocorreu com a lei dos transplantes, no tocante a alguns dos crimes que descreve. Apesar de poderem ser subsumidos a tipos penais já existentes, a especificidade do contexto em que a conduta é praticada justificou a criação de tipo penal específico.

A peculiaridade do contexto em que as pesquisas são realizadas, além de justificar a elaboração da lei penal a respeito do tema, também permite a elaboração de tipos penais outros, adicionais àqueles existentes no ordenamento jurídico vigente, aptos a abarcar eventuais condutas criminosas praticadas nesse meio - ou seja, a dignidade penal e a carência de tutela penal na espécie existem sem prejuízo do disposto no Código Penal e em leis penais especiais.

É forçoso ainda reconhecer que a criação de lei penal específica poderia inibir a prática de condutas criminosas nas pesquisas envolvendo seres humanos, dada a função preventiva que a pena assume, ao lado da função retributiva que também lhe é comum (art. 59, CP). Dessa maneira, a elaboração de lei penal acerca das pesquisas envolvendo seres humanos permitiria definir quais as condutas criminosas praticadas contra os sujeitos de pesquisa ou contra qualquer outra potencial vítima, como, por exemplo, a coletividade, e possibilitaria estabelecer mecanismos para a prevenção e redução dessas práticas, além de dispor sobre as formas de assistência às vítimas.

\section{Consentimento livre e esclarecido}

Na presente discussão, deve-se também abordar a importante questão relativa ao consentimento. A Resolução CNS 196/96 define consentimento como anuência do sujeito da pesquisa e/ou de seu representante legal, livre de vícios (simulação, fraude ou erro), dependência, subordinação ou intimidação, após explicação completa e pormenorizada sobre a natureza da pesquisa, seus objetivos, métodos, benefícios previstos, potenciais de riscos e o incômodo que esta possa acarretar, formulada em um termo de consentimento, autorizando sua participação voluntária no experimento ${ }^{5}$.

As resoluções CNS 251/97 e 340/04 também tratam do consentimento nas pesquisas envolvendo seres humanos. A primeira aborda o consentimento de pacientes com capacidade reduzida ou não desenvolvida, bem como pacientes psiquiátricos. A segunda, contempla situações de pesquisas envolvendo genética humana. Assim, menciona os requisitos mínimos do termo de consentimento livre e esclarecido nessas hipóteses.

O termo de consentimento deve ser redigido conforme as diretrizes traçadas pela Resolução CNS 196/96 e, sequencialmente, ser aprovado pelos comitês das instituições em que a pesquisa for realizada. Somente então será aplicado ao sujeito de pesquisa, possibilitando que essa tenha início.

De acordo com Goldim, o consentimento informado é direito moral dos pacientes, que gera obrigações morais para os médicos. É composto por três elementos básicos: competência ou capacidade (capacidade de pensar e deliberar), informação (dar a conhecer os riscos, benefícios, desconfortos e implicações econômicas de procedimentos assistenciais ou experimentais, objetivando que as pessoas tomem decisões devidamente esclarecidas) e consentimento (escolha voluntária feita pelo indivíduo, livre de coerção do médico, do pesquisador, de outros profissionais de saúde, familiares, amigos ou da própria sociedade).

O autor destaca que o consentimento deve ser visto como um processo e não como um evento, sendo que haverá violação a esse processo quando faltarem informações adequadas ou quando houver falha na obtenção do consentimento ${ }^{16}$.

De qualquer maneira, o termo de consentimento livre e esclarecido tem por objetivo proteger o sujeito de pesquisa. Sua previsão nas resoluções anteriormente mencionadas permite o estabelecimento de diretrizes para a atuação dos agentes envolvidos na pesquisa, quais sejam: a instituição, o pesquisador, o patrocinador etc. A adequação do termo de consentimento às diretrizes traçadas nas resoluções já referidas é fundamental, vez que a correta informação do sujeito de pesquisa acerca do procedimento a que será submetido é a base para a tomada de uma decisão autônoma.

Nesse sentido, não apenas a informação, mas, sobretudo, o esclarecimento deve estar presente. Ou seja, as informações prestadas devem ser adaptadas ao nível intelectual e cultural do sujeito de 
pesquisa, a fim de possibilitar a adequada compreensão do termo de consentimento. Claro está, portanto, que o termo de consentimento configura direito moral dos pacientes - no caso, dos sujeitos de pesquisa. Assim, deve ser perfeito quanto aos elementos que o integram e que foram acima referidos.

\section{Consentimento, tipificação penal e disponibi- lidade dos bens}

Nesse ponto, deve-se fazer uma ressalva acerca da temática envolvendo consentimento e tipificação penal. Trata-se, na verdade, da problemática que envolve o consentimento do ofendido na prática do fato típico, que pode configurar-se mediante três hipóteses.

A primeira trata do consentimento como causa de exclusão da tipicidade. É o caso, por exemplo, da prática de conjunção carnal com o consentimento da pessoa, hipótese indubitavelmente atípica. Não havendo consentimento, contudo, ou sendo ele fornecido por quem não seja capaz de fazê-lo, estará configurado o crime previsto no art. 213 do Código Penal, qual seja, estupro.

Na segunda hipótese vislumbra-se o consentimento como elemento integrante do tipo penal. Nesse sentido, pode-se mencionar a provocação de aborto com o consentimento da gestante, tipo penal previsto no art. 124 do Código Penal.

Por fim, há a hipótese em que o consentimento figura como causa de exclusão da ilicitude - ou seja, embora típico, o fato não é antijurídico. Interessa saber, contudo, da validade de se consentir, de se dispor dos bens jurídicos envolvidos na presente discussão.

A esse respeito, Aníbal Bruno ensina que para funcionar como causa de exclusão do ilícito deve o consentimento decorrer de vontade juridicamente válida. Aquele que consente deve ser capaz de querer com eficácia jurídica, e o consentimento deve exprimir a sua vontade real, ser voluntário, não obtido por violência ou erro essencial. Só pode concedê-lo validamente o titular do bem jurídico, aquele que dele pode legitimamente dispor ${ }^{17}$. A possibilidade de se dispor dos bens jurídicos apenas existe, portanto, quando se tratar de bens disponíveis, bens sobre os quais predomina o interesse privado.

Nesses casos o consentimento é capaz de excluir a antijuridicidade da conduta. Assim, pode-se consentir, por exemplo, em que se danifique determinado bem material, pois se trata de bem dispo- nível. Ao se tratar de bens indisponíveis, todavia, a solução é outra, vez que predomina o interesse coletivo, tutelado pelo Estado, ainda que o ofendido consinta com a ofensa.

Na presente análise estão abrangidas a vida e a integridade física, bens indisponíveis, passíveis de serem violados quando da realização de pesquisas envolvendo seres humanos. Não se pode consentir, por exemplo, com lesões físicas ao próprio corpo. Da mesma forma, não se pode consentir com a própria morte. É claro que exceções como a possibilidade de se consentir com a doação de um órgão em vida rim, por exemplo - existem. Assim, não se tipifica o crime de lesão corporal, pois o consentimento afasta a antijuridicidade da conduta na espécie.

Entretanto, o que aqui se discute é a possibilidade de que o consentimento, fornecido por ocasião da assinatura do termo de consentimento livre e esclarecido, afaste a antijuridicidade de eventual conduta, penalmente tipificada para tutelar os bens indisponíveis acima referidos - vida e integridade física - e porventura violados em pesquisas envolvendo seres humanos. Com efeito, a vida e a integridade física das pessoas não podem estar sujeitas à livre disposição, estreme de qualquer limite. São constitucionalmente tuteladas e atreladas à dignidade da pessoa humana.

Não têm validade os atos jurídicos pelos quais uma pessoa coloca sua vida à disposição ou se submete a grave perigo. Ainda que se trate de experimentação científica, a ordem pública e os bons costumes devem ser considerados, de forma a evitar que abusos ocorram. Assim, faz-se forçoso reconhecer que a integridade física deve ser preservada, haja vista que integra os atributos da pessoa humana.

Destarte, ainda que existente um termo de consentimento que manifeste concordância com práticas possíveis de atingir os bens jurídicos mencionados, este não poderá afastar eventual responsabilidade penal na espécie, conforme explicado. Corrobora tal entendimento o disposto no art. 13 do Código Civil: Salvo por exigência médica, é defeso o ato de disposição do próprio corpo, quando importar diminuição permanente da integridade física ou contrariar os bons costumes ${ }^{18}$.

Parece-nos que a existência do termo de consentimento livre e esclarecido não seria apta a afastar a antijuridicidade da conduta, não sendo, portanto, garantia de que a responsabilidade penal do pesquisador ou de qualquer outro agente envolvido na pesquisa - apurada na medida de sua cul- 
pabilidade, nos termos do art. 29 do Código Penal seria afastada. Nos casos em que houvesse violação ao processo de obtenção de consentimento, acredita-se que a hipótese seria a previsão de uma causa de aumento de pena para os tipos criados, a ser aplicada na terceira fase de fixação da pena, podendo, assim, ultrapassar o limite máximo da pena base.

A dignidade penal, portanto, parece estar presente independentemente da existência ou não do termo de consentimento. As condutas a serem criminalizadas deveriam ser similares àquelas praticadas pelos cientistas e não meras práticas que destoam da nossa realidade, devendo-se salientar que a construção dos tipos penais há de ser rigorosa, de forma a não dificultar o desenvolvimento biotecnológico do país.

\section{Considerações finais}

Ao longo do presente trabalho desenvolveu-se um raciocínio segundo o qual há dignidade penal e carência de tutela penal nas pesquisas em seres humanos. Assim, asseverou-se que já houve na história da humanidade situações graves o bastante para demonstrar a necessidade da referida tutela e a carência de instrumentos aptos a garantir a imperatividade de documentos que regulam essa matéria, a exemplo do Código de Ética Médica.

Viu-se que apenas o Estado, coercitivamente, pode assegurar o desenvolvimento da biomedicina de forma a respeitar a pessoa humana como um fim em si mesma, sendo que a criação de tipos penais, em virtude dos princípios da legalidade e da taxatividade, traria a segurança que se espera do Direito Penal. Salientou-se ainda que a vida, a integridade física e a dignidade da pessoa humana, em razão da importância que possuem, fazem com que o Direito Penal seja, nessas hipóteses de pesquisas envolvendo seres humanos, o meio estatal mais eficaz para sua tutela.

Também se discorreu sobre a idoneidade da tutela penal acerca dessa matéria, sobretudo em razão da experiência de outros países, em que apenas a criação de tipos penais revelou-se apta a tratar do assunto. Foi igualmente dito que a existência de termo de consentimento para a realização dessas pesquisas é necessária, não afastando, contudo, a responsabilidade penal eventualmente existente, vez que a vida e a integridade física devem ser preservadas, não estando sujeitas à livre disposição.

\section{Referências}

1. Pantaleão JF. Riscos de uma sociedade e uma sociedade de risco. In: Toledo A, coordenador. Direito penal: reinterpretação à luz da Constituição: questões polêmicas. Rio de Janeiro: Elsevier; 2009. p. 260.

2. Brasil. Constituição (1988). Constituição da República Federativa do Brasil. Brasília, DF: Senado; 1988.

3. Tavares J. Critérios de seleção de crimes e cominação de penas. Revista Brasileira de Ciências Criminais. 1992;(0):75-87. Número especial de lançamento.

4. Hossne WS. Pesquisa envolvendo seres humanos: capacitação para comitês de ética em pesquisa. Brasília: Ministério da Saúde; 2006. p. 116.

5. Conselho Nacional de Saúde (Brasil). Resolução n 1, de 13 de junho de 1988. Aprova normas de pesquisa em saúde. Diário Oficial da União. 14 jun. 1988; seção 1.

6. Conselho Nacional de Saúde (Brasil). Resolução n 196, de 10 de outubro de 1996. Aprova normas regulamentadoras de pesquisas envolvendo seres humanos. Diário Oficial da União. 16 out. 1996;(201)Seção 1:21082-5

7. Oliveira PH, Anjos Filho RN. Bioética e pesquisas em seres humanos. Revista da Faculdade de Direito da Universidade de São Paulo. 2006;101:1187-230.

8. Minahim MA. A vida pode morrer? Reflexões sobre a tutela penal da vida em face da revolução biotecnológica. In: Barbosa HH; Barreto VP, organizadores. Novos temas de biodireito e bioética. Rio de Janeiro: Renovar; 2003.

9. Bianchini A. Pressupostos materiais mínimos da tutela penal. São Paulo: Ed. Revista dos Tribunais; 2002.

10. Diez Ripolles JL. A racionalidade das leis penais: teoria e prática. São Paulo: Ed. Revista dos Tribunais; 2005. p. 92.

11. Oliveira RA, Segre M. Pesquisa em ética. In: Segre M, organizador. A questão ética e a saúde humana. São Paulo: Atheneu; 2006. p. 50

12. Conselho Federal de Medicina. Resolução n 1.931, de 17 de setembro de 2009. Aprova o Código de Ética Médica. Diário Oficial da União. 24 set. 2009;Seção 1:90-2. Retificada em Diário Oficial da União. 13 out. 2009;Seção 1:173. 
13. Tengen C, Venancio PC, Marcondes FK, Rosalen PL. Autonomia e vulnerabilidade do sujeito da pesquisa. Revista de Direito Sanitário. 2005;6(1-3):31.

14. Sant'Anna AA. A nova genética e a tutela penal da integridade física. Rio de Janeiro: Lumen Júris; 2001.

15. Brasil. Lei $n^{\circ} 11.340$, de 7 de agosto de 2006. Cria mecanismos para coibir a violência doméstica e familiar contra a mulher, nos termos do $\S 8^{\circ}$ do art. 226 da Constituição Federal, da Convenção sobre a Eliminação de Todas as Formas de Discriminação contra as Mulheres e da Convenção Interamericana para Prevenir, Punir e Erradicar a Violência contra a Mulher; dispõe sobre a criação dos Juizados de Violência Doméstica e Familiar contra a Mulher; altera o Código de Processo Penal, o Código Penal e a Lei de Execução Penal; e dá outras providências. [internet]. 2006 [acesso nov. 2010]. Disponível: http://www.planalto.gov.br/ccivil_03/_ato2004-2006/2006/lei/l11340. htm

16. Goldim JR. Consentimento informado. [internet]. 1997 [acesso $1^{\circ}$ nov. 2010]. Disponível: http:// www.bioetica.ufrgs.br/consinf.htm

17. Bruno A. Direito Penal: parte geral. Rio de Janeiro: Editora Nacional de Direito; 1956. t. 2. p. 403.

18. Brasil. Código Civil (2002). Código Civil brasileiro. Brasília: Senado; 2002.

\section{Participação dos autores}

Talita Ferreira participou da concepção, análise e redação do artigo. Cláudio Cohen participou da revisão crítica do artigo. Reinaldo Ayer participou da análise e revisão crítica do artigo.

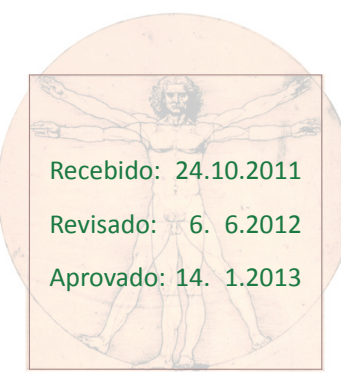

